\title{
UNIPOLAR ELECTROCARDIOGRAPHY IN PULMONARY STENOSIS
}

\author{
BY \\ R. M. MARQUIS* \\ From the Royal Infirmary, Edinburgh \\ Received July 13, 1950
}

Congenital pulmonary stenosis with intact ventricular septum is a relatively common malformation of the heart. The stenosis varies from almost complete obliteration to a minimal decrease in the diameter of the orifice. The stenosis is usually of the valve, but it may be either of the infundibulum or of the lower bulbar orifice. The atrial septum may be complete, imperfectly developed, or it may be fenestrated: there is often anatomical patency of the foramen ovale, which may or may not allow the passage of blood from the right to the left atrium during life. The pulmonary artery beyond the stenosis is usually dilated and thin-walled, but it may be normal.

These variations make for wide diversity in the clinical features of the malformation. It is often a relatively benign lesion, but in its most severe form death occurs within the first year of life (Freed and Budnitz, 1946). Intermediate between these extremes is the group in which infancy is survived and childhood relatively symptomless but, sooner or later, there is increasing exertional dyspnœa, with or without cyanosis, leading on to congestive heart failure or sudden death. The work of Brock $(1948,1949)$ on valvulotomy and infundibular (or lower bulbar) resection has made this latter group of great clinical and diagnostic importance.

In spite of the anatomical and clinical variations, the increased work of the right ventricle depends essentially on the severity of the stenosis in relation to the right ventricular output. The extent of the right ventricular hypertrophy is, therefore, an indication of the severity of the lesion, even in the absence of disability, cyanosis, and clinical deterioration. By recording the degree and development of this hypertrophy, unipolar electrocardiography is of great assistance in the assessment of the malformation.

The purpose of this paper is to demonstrate the characteristic cardiographic pattern of the extreme right ventricular hypertrophy that develops in pulmonary stenosis. The significance of this pattern is discussed in relation to diagnosis, prognosis, and surgical treatment of this congenital defect.

\section{EleCtrocardiographic Features}

Dow et al. (1950) have demonstrated by cardiac catheterization that pulmonary stenosis may exist for many years without disability and without electrocardiographic evidence of right ventricular hypertrophy. There may be right bundle branch block (Blackford and Parker, 1941; Auerbach and Harper, 1947), or the cardiographic picture of moderate to marked right ventricular hypertrophy (Currens, Kinney, and White, 1945; Lowance et al., 1948). Right ventricular preponderance with large, pointed $\mathbf{P}$ waves in lead II, a tendency to lengthening of the $\mathbf{P}-\mathbf{R}$ interval, and frequent inversion of the T waves in leads II and III, have been described by Allanby and Campbell (1949); they also report tall $\mathrm{R}$ waves extending across the chest in the three cases in whom they recorded unipolar chest leads. In the most severe grades of pulmonary stenosis and atresia, comparable

* Work done during tenure of the Kirk Duncanson Research Fellowship of the Royal College of Physicians, Edinburgh. 
standard lead patterns have been recorded in infancy (Freed and Budnitz, 1946; Brown, 1949). Selzer et al. (1949), using CR leads, recorded the pattern of extreme right ventricular hypertrophy.

It is considered that this pattern is characteristic in the fully developed picture of pulmonary stenosis with intact ventricular septum. The form of the limb leads may vary with the position of the heart, but the usual features are gross right axis deviation, tall, pointed P waves in lead II, S-T depression, and deep T wave inversion in lead III and usually in lead II. In the unipolar limb leads, aVR shows a variable $Q$, tall $R$, and upright or inverted $T$ wave; aVL shows a small $r$, deep $S$, and upright $\mathrm{T}$ wave; and aVF shows a small $\mathrm{q}$, tall $\mathrm{R}, \mathrm{S}-\mathrm{T}$ depression, and deep $\mathrm{T}$ wave inversion. The unipolar chest leads show the most marked changes of right ventricular hypertrophy seen in clinical cardiography. There are tall $R$ waves, $S-T$ depression, and deeply inverted $T$ waves that extend far across the chest towards the left. The greatest degree of right ventricular hypertrophy is characteristically recorded from the left of the sternum-V2, V3, or even V4. Necropsy findings prove that the unipolar chest leads are thus faithful recorders of the hypertrophy of the underlying myocardium.

\section{CASE SUMmarifs}

Case 1. A boy, aged 5 years, who had experienced little disability apart from a tendency to fainting attacks on exertion. He was not cyanosed. There was gross cardiac enlargement and, on radioscopy, immense dilatation of the pulmonary artery. The electrocardiogram in Fig. 1* was recorded shortly before he dropped dead on his way to school.

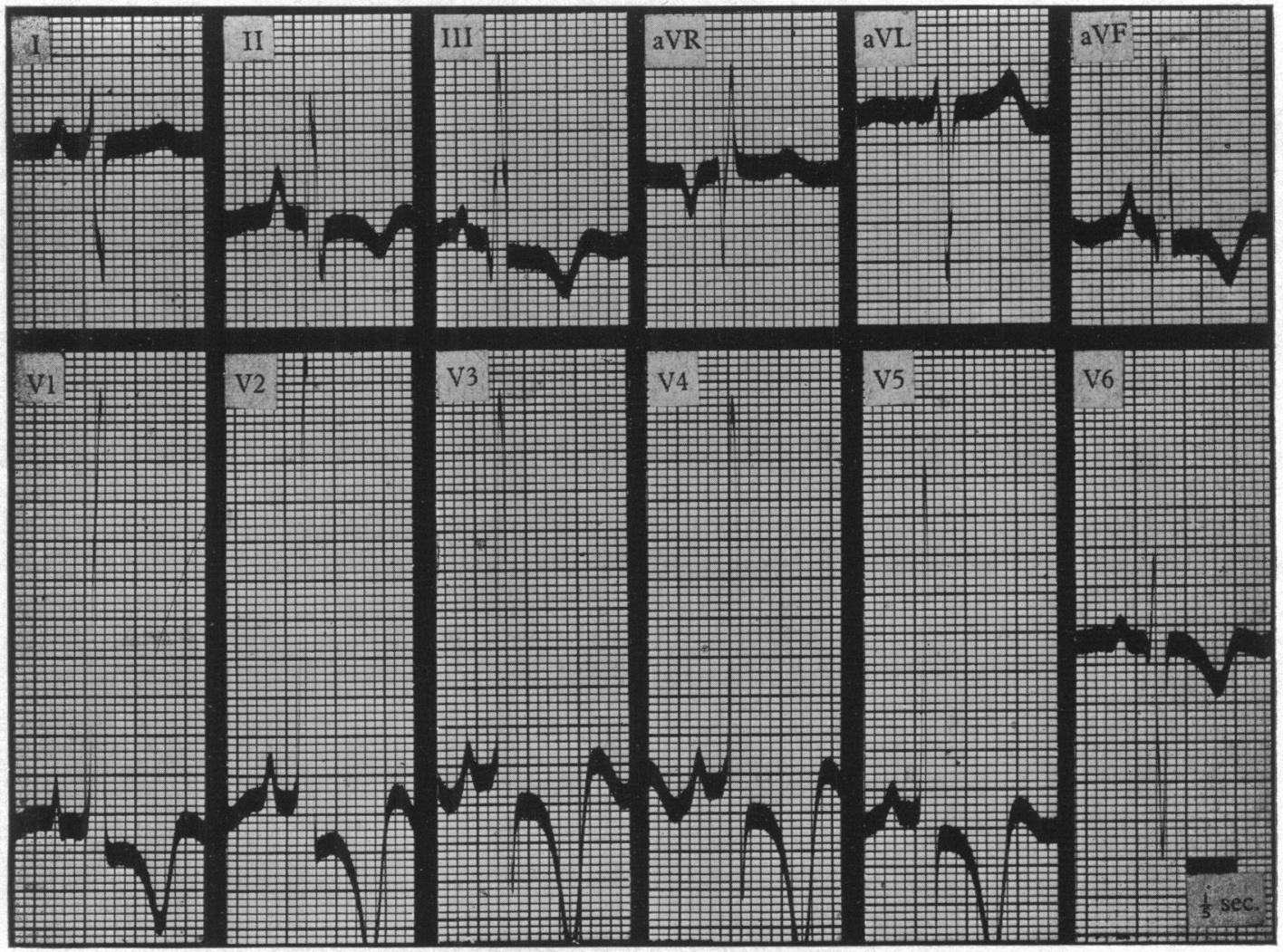

Fig. 1.-Electrocardiogram of Case 1. The fully developed pattern of extreme right ventricular hypertrophy. At necropsy there was valvular pulmonary stenosis, intact ventricular septum, closed foramen ovale, and poststenotic dilatation of pulmonary artery.

* This electrocardiogram has been previously reported in a review of unipolar electrocardiograms (Hill, I. G. W. (1950), Lancet, 1, 1027). 
Post mortem, there was a severe grade of valvular pulmonary stenosis (diameter at apex of cone measured $3.5 \mathrm{~mm}$.). The foramen ovale was anatomically closed and the right ventricular wall was approximately twice as thick as the left (àverage thickness, $16 \mathrm{~mm}$.).

Case 2. A boy, aged 13 years, who had been cyanosed at rest and breathless on exertion since 6 months of age. These features became more striking when he started to walk at 12 months. Throughout his life he was severely handicapped, thin, and grossly underweight. He squatted in the best Fallot tradition. There was slight cardiac enlargement on radioscopy and the left pulmonary artery was dilated. His general condition deteriorated rapidly during the last year of his life. The electrocardiogram in Fig. 2 was recorded a few days before he died suddenly during thoracotomy.

Post mortem, there was a severe grade of valvular pulmonary stenosis (diameter at apex of cone

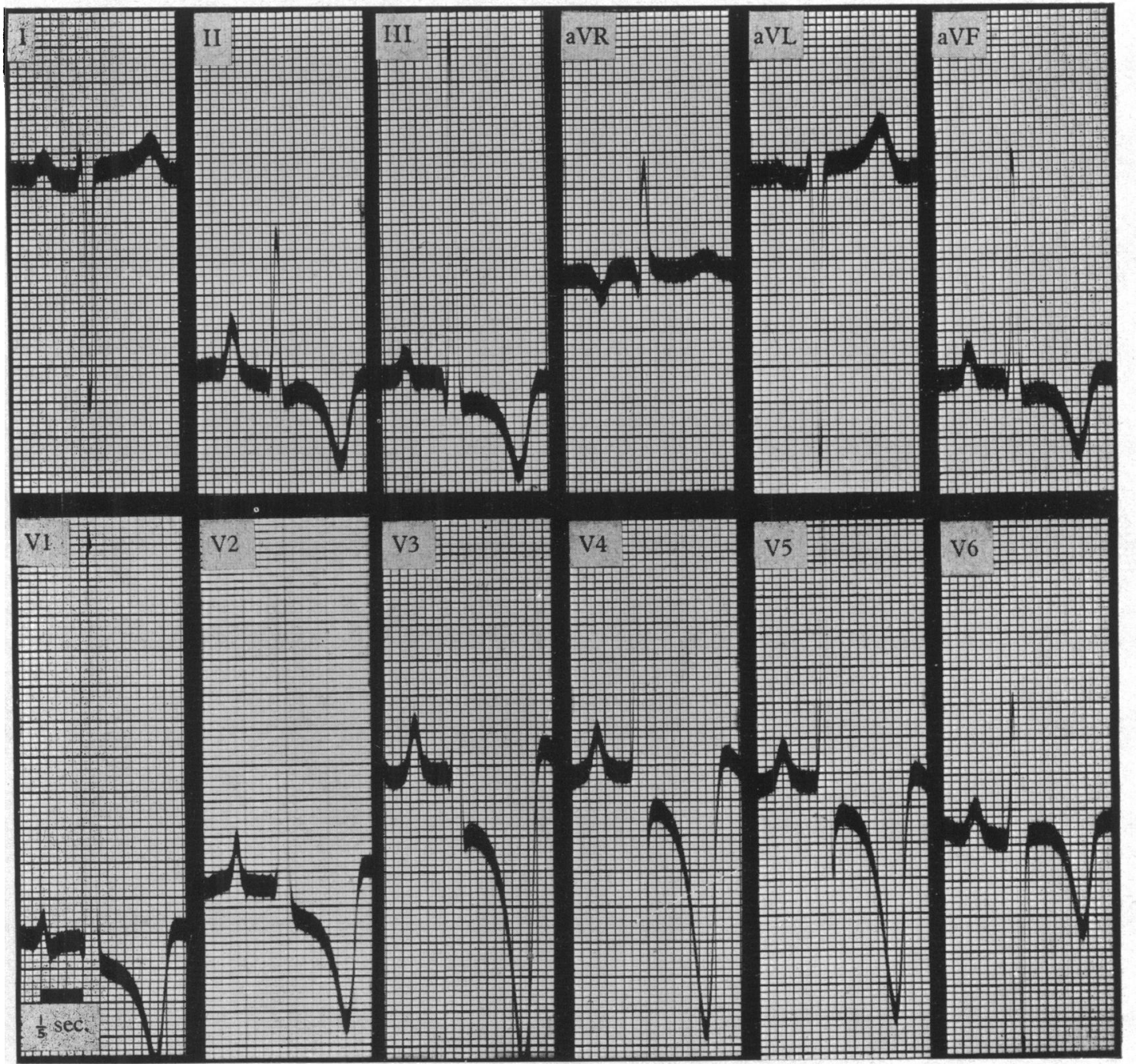

FIG. 2.-Electrocardiogram of Case 2. The fully developed pattern of extreme right ventricular hypertrophy. Voltage of QRS complexes in chest leads at normal sensitivity was such that the peaks of the $R$ and $S$ waves were not recorded. At $1 / 2 \mathrm{~N}$ sensitivity tall $R$ waves extended from $V 1$ to $V 5$ as the main initial deflections. At necropsy there was valvular pulmonary stenosis, intact ventricular septum, fenestrated atrial septal defect, and post-stenotic dilatation mainly of left pulmonary artery. 
was $3.5 \mathrm{~mm}$.). There was a fenestrated atrial septal defect of $15 \mathrm{~mm}$. diameter and the right ventricle was approximately twice as thick as the left (average thickness, $17 \mathrm{~mm}$.).

Case 3. A boy, aged 5 years, in whom congenital heart disease was diagnosed for the first time on routine school medical examination. Since that time he had been thought to be slightly breathless and cyanosed on severe exertion. In spite of this he was a keen footballer and was able to play centre-half in his local school team. There was moderate cardiac enlargement, prominence of the conus of the right ventricle, but no dilatation of the pulmonary artery on radioscopy. During the next 6 years there was no change in his clinical or radiological features. The electrocardiogram in Fig. 3B was recorded when he was 12 years of age. A year later he died suddenly after attending a fair.

Post mortem, he had a severe grade of infundibular stenosis which involved the pulmonary

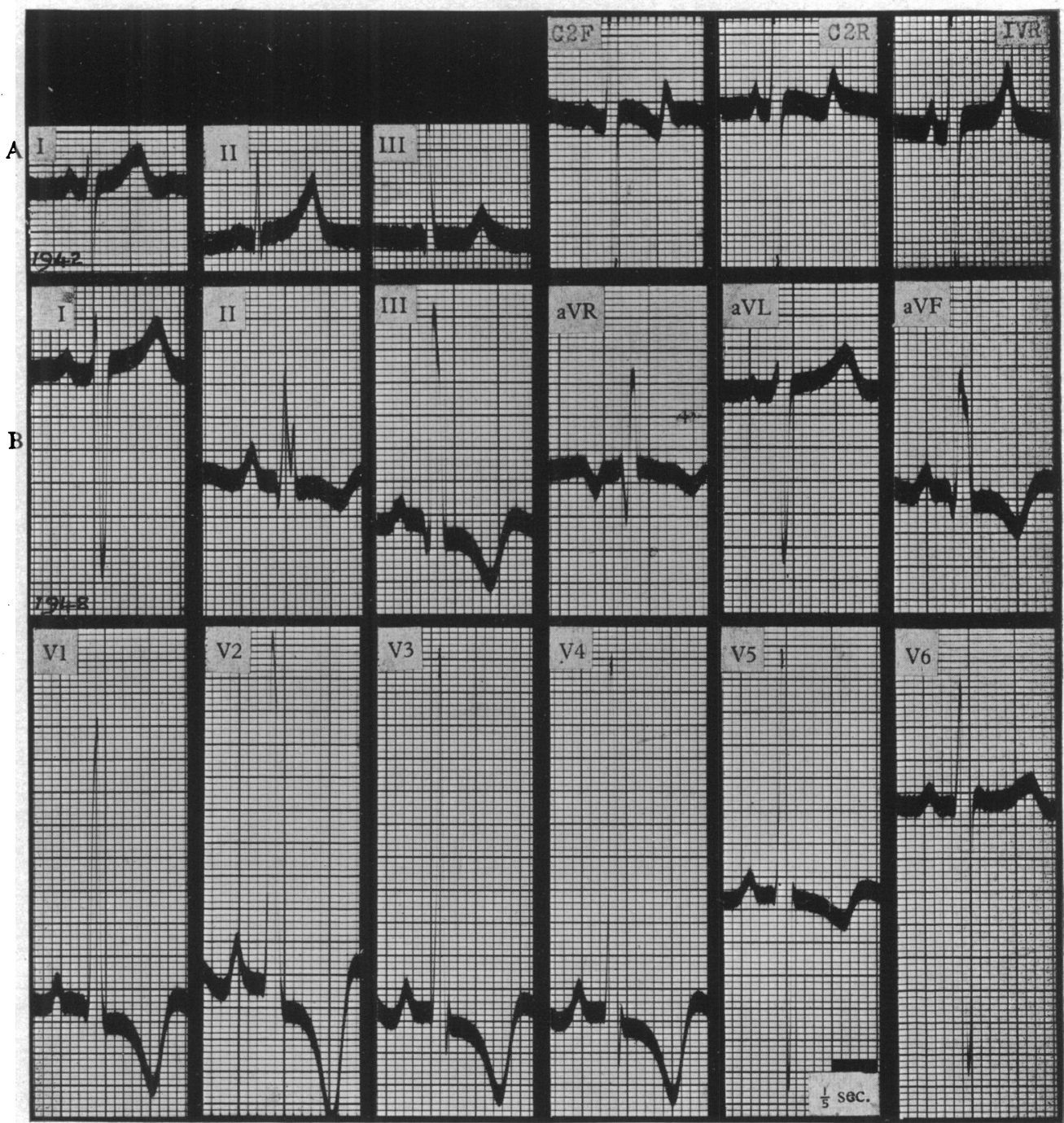

Fig. 3.-Electrocardiogram of Case 3. (A) At 5 years of age. Right axis deviation. Small P waves in lead II. (B) At 12 years of age. Extreme right ventricular hypertrophy. At necropsy there was infundibular pulmonary stenosis, intact ventricular septum, small valvular foramen ovale, without any post-stenotic dilatation of pulmonary artery. 
valves, extended for $25 \mathrm{~mm}$. into the right ventricle, and had a diameter of $5 \mathrm{~mm}$. An anatomically patent foramen ovale measured only $2 \mathrm{~mm}$. diameter and was covered by a well-formed septum secundum. The right ventricle was approximately twice as thick as the left (average thickness, $19 \mathrm{~mm}$.).

Case 4: A girl, aged 9 years, when first seen in 1944. She was little disabled, except by an oversolicitous mother, and there has been no clinical deterioration during 6 years of follow-up. Radioscopic examination showed no increase in heart size (Fig. 4), but there have been well-marked

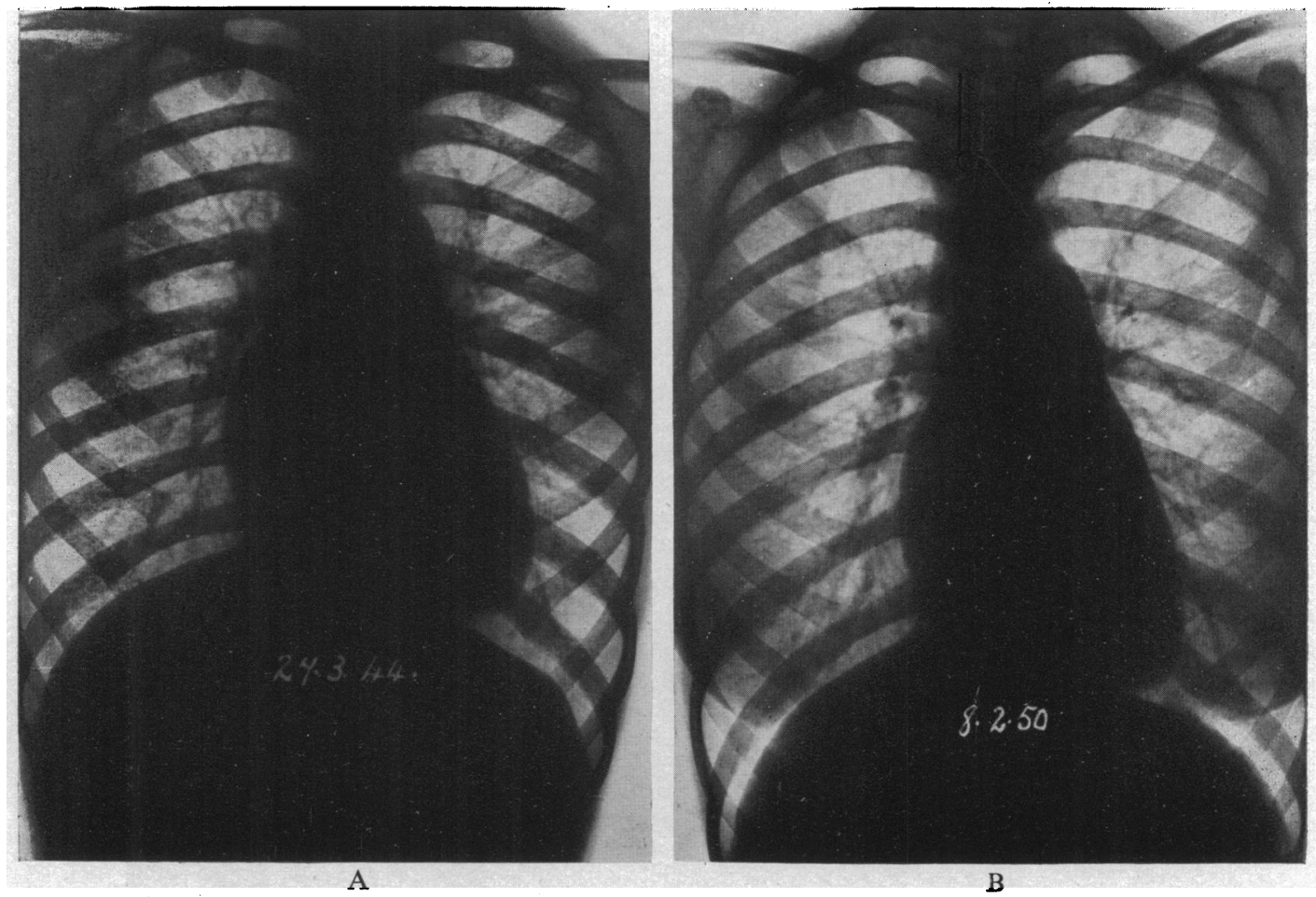

Fig. 4.-Radiograph (anterior) of Case 4. (A) At 9 years of age. (B) At 15 years of age. Vertical type of heart shadow, prominence of right border, prominent pulmonary artery segment, diminished vascularity of lung fields. No increase in cardiothoracic ratio during 6 years of follow-up.

electrocardiographic changes. At 9 years of age (Fig. 5A), $\mathrm{P}$ wave was already more than $3 \mathrm{~mm}$. in height in lead II and the T waves were inverted in leads III and C2F. Four years later, after a period of enforced, but unnecessary, invalidism, there had been no significant change in the standard leads; unipolar leads, which were then recorded for the first time, showed tall $\mathbf{R}$ waves followed by deep $\mathrm{T}$ inversion in V1 and V2, but not beyond. During the next two years her mother was encouraged to let her lead a more normal life and by 15 years of age the $T$ wave had become inverted in lead II and tall $R$ waves and inverted T waves extended across the chest to V5 (Fig. 5B).

Case 5. A girl, aged 9 years when first seen. At that time she experienced slight exertional dyspnœa but no real disability in spite of considerable cardiac enlargement (Fig. 6). Two years later her clinical and radiological condition remained unchanged but she was sometimes very tired after a full-length gymnastic class at school. Unipolar electrocardiograms, in contrast, revealed marked and rapidly developing changes (Fig. 7).

Case 6. A young married woman, aged 27 years when first seen. At that time she had given birth to two children with relative ease and was admitted to hospital on account of pulmonary tuberculosis. Electrocardiogram showed advanced changes of right ventricular hypertrophy with 


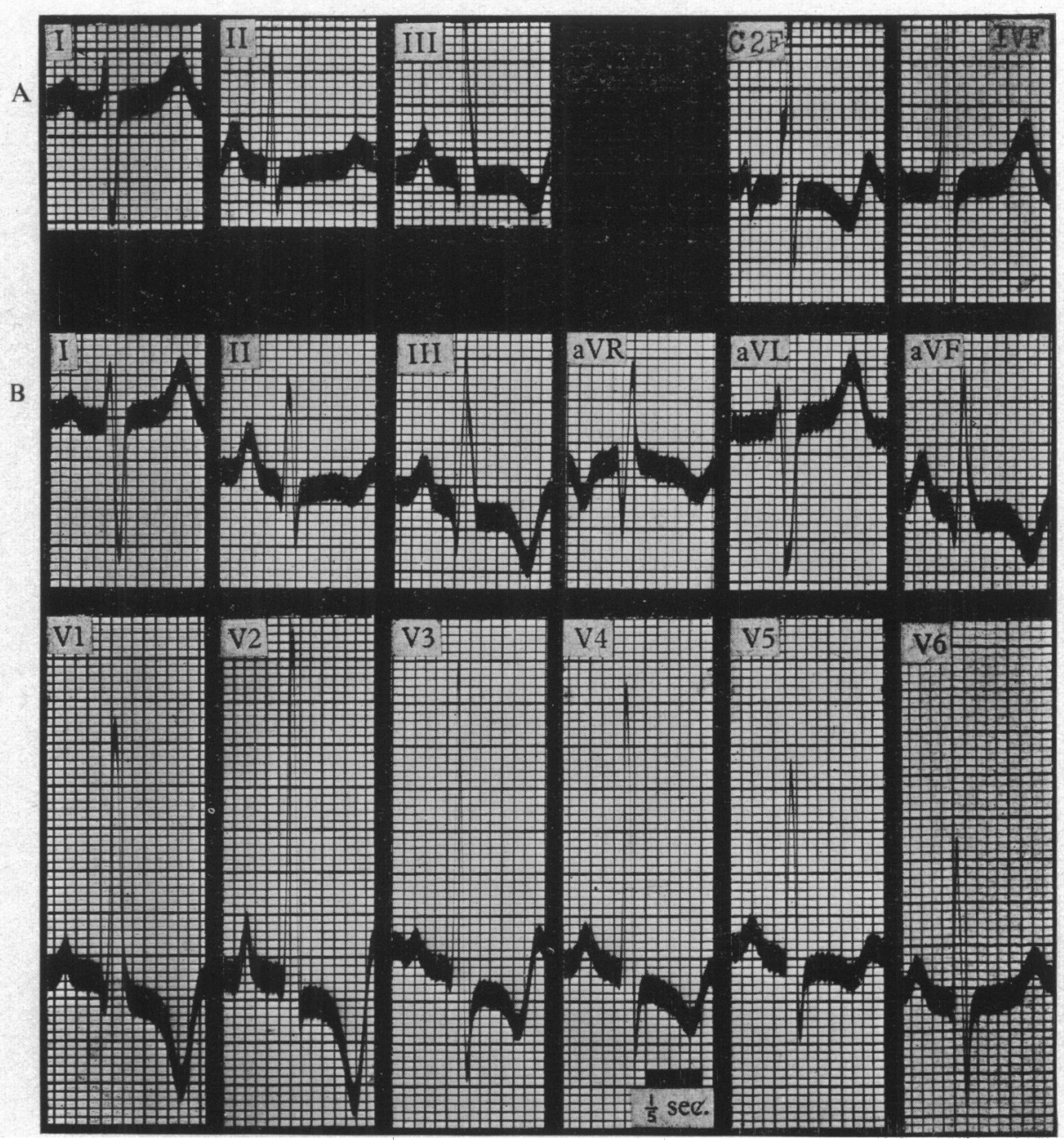

FIG. 5.-Electrocardiogram of Case 4. (A) At 9 years of age. Right axis deviation, P wave over $3 \mathrm{~mm}$. in lead II, and inverted $\mathrm{T}$ wave in leads III and C2F. (B) At 15 years of age. Pattern of extreme right ventricular hypertrophy although the heart is not enlarged on radioscopy (Fig. 4).

$P$ waves over $4 \mathrm{~mm}$. in height in lead II, marked right axis deviation, S-T depression and inverted $\mathrm{T}$ waves in leads II, III, and C2F, and a sharply diphasic T wave in IVF. Radioscopy showed the size of the cardiovascular shadow to be within normal limits but the shape suggested right ventricular hypertrophy and the pulmonary artery was enlarged. During the next three years the pulmonary tuberculosis extended to involve both lungs. She had repeated hæmoptyses, increasing exertional dyspnœa, tiredness, and intermittent œdema of the ankles. She was never observed to be cyanosed. Her eventual death at 30 years of age was due to massive hæmoptysis.

Post mortem, there was valvular pulmonary stenosis of moderate severity (diameter at apex of cone, $8 \mathrm{~mm}$.); anatomical patency of the foramen ovale which, although valvular in type, had a diameter of $9 \mathrm{~mm}$.; the right ventricular wall was one and a half times as thick as the left (average thickness, $22 \mathrm{~mm}$.).

Case 7. A boy, aged 13 years when he was first seen. At that time he had suffered from progressive exertional dyspnœa and cyanosis since 5 years of age. He was severely limited in his activities and complaining of frequent " dizzy turns" on exertion. Radioscopy showed slight 


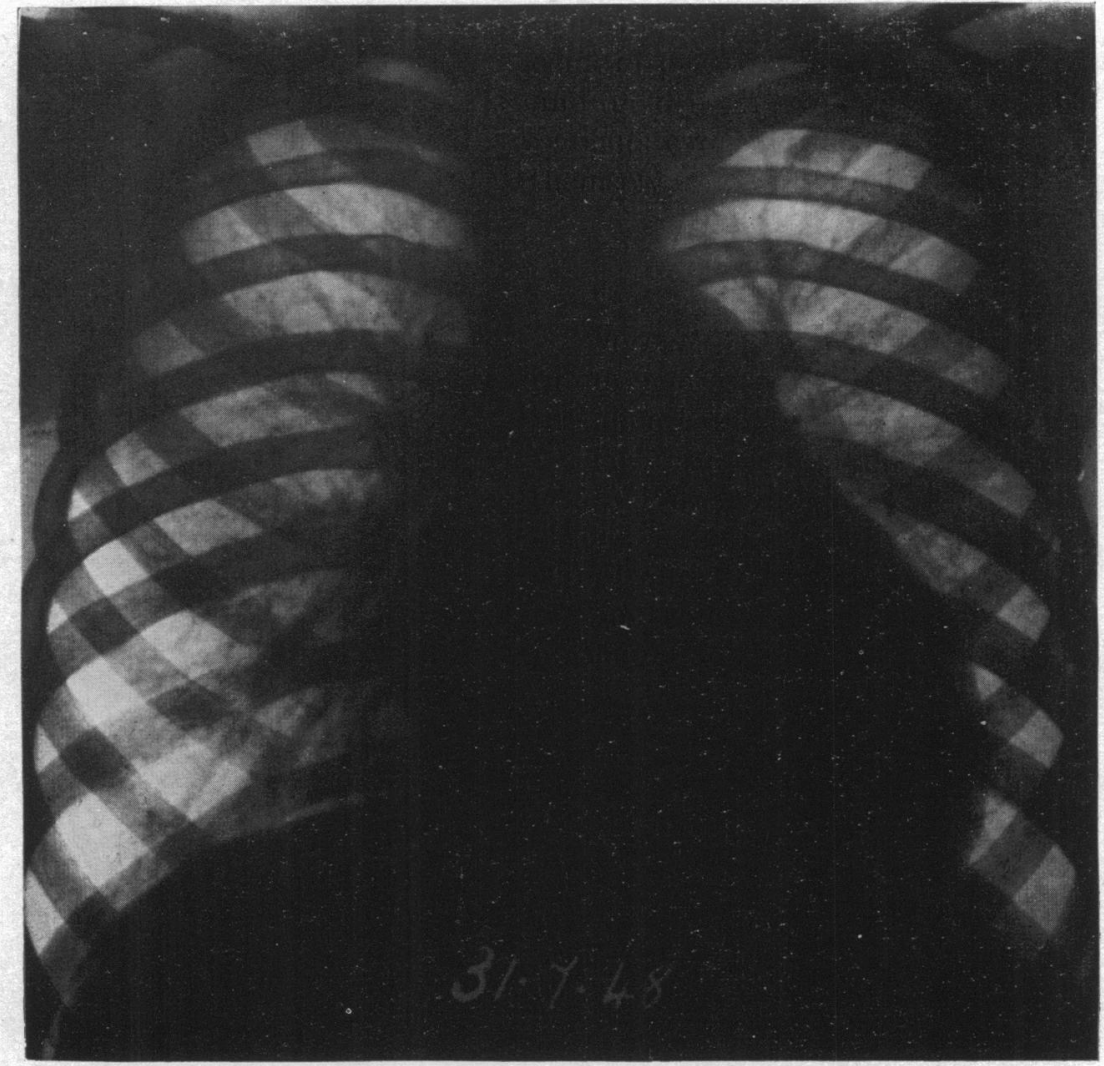

FIG. 6.-Radiograph (anterior) of Case 5 at 9 years of age. Considerable cardiac enlargement, increased convexity of right border of heart, well marked enlargement of pulmonary artery segment, and hilar shadows normal but small in relation to heart size. There has been no increase in heart size during two years of follow-up.

cardiac enlargement and prominence of the pulmonary artery and its left main branch. Cardiographic examination (Fig. 8A) showed well-advanced right ventricular hypertrophy with deep inversion of the $T$ wave in $C 2 F$. Six months later he developed subacute bacterial endocarditis, but after a 28 -day course of penicillin ( 0.5 mega units daily) made a remarkable recovery. Like the case reported by Pollack et al. (1948), the bacterial infection performed an effective " valvulotomy." Before the acute illness he could not run the length of a football field; after recovery he played a full game every Saturday. The $T$ wave became less inverted in lead C2F. At 18 years of age he now admits to little cardiac disability, he is no longer cyanosed, and in spite of full-time work and greatly increased activity there has been no evidence of increased right ventricular hypertrophy (Fig. 8B).

\section{Discussion}

These cases illustrate the developing and fully developed electrocardiographic pattern of extreme right ventricular hypertrophy common in the severer grades of pulmonary stenosis when the ventricular septum is intact. Their similarity suggests that the development of this pattern is independent of clinical or radiological variation, the state of the atrial septum, the exact site of the stenosis and, as would be expected, the state of the pulmonary artery beyond the stenosis. 


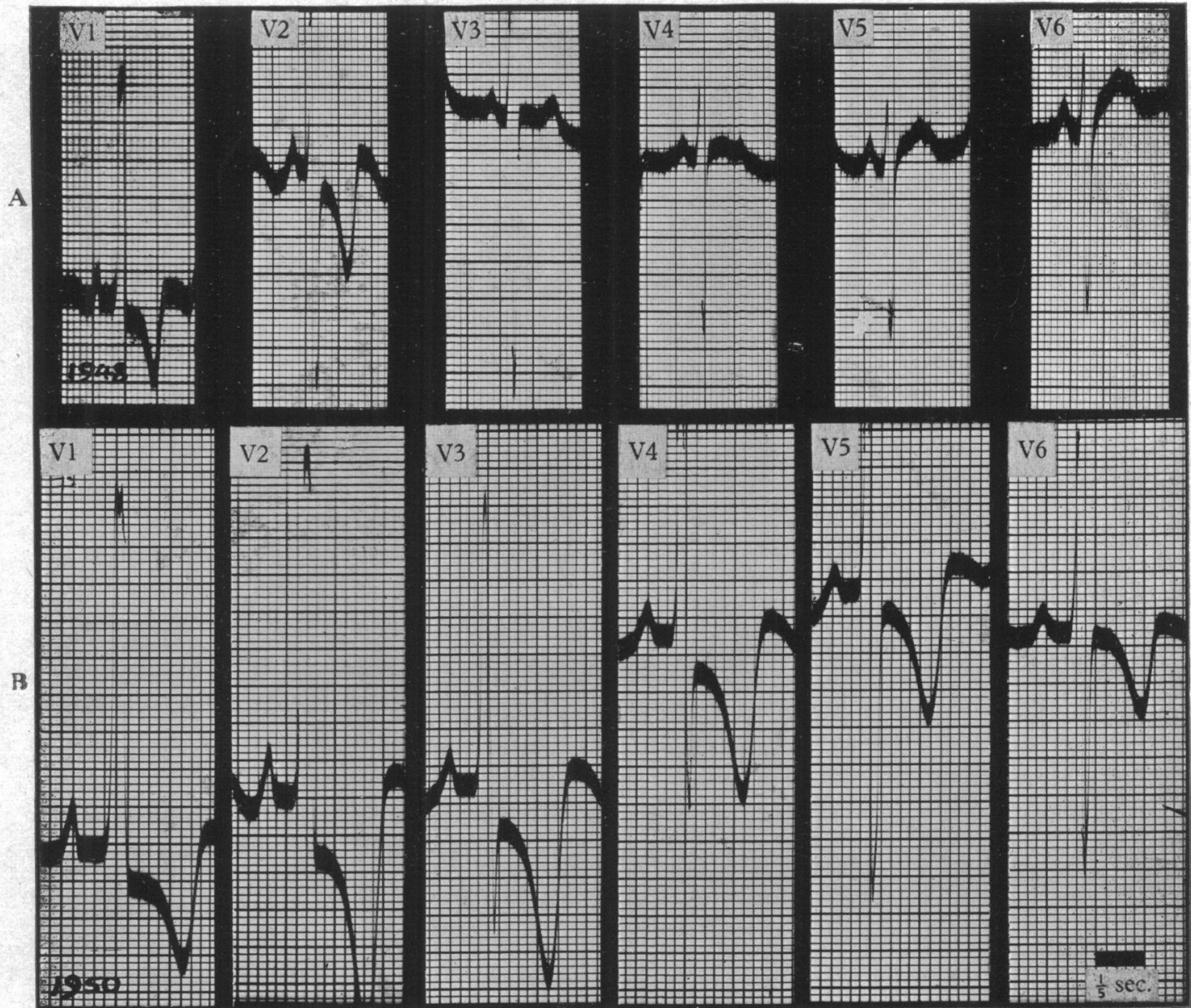

Fig. 7.-Electrocardiogram of Case 5. (A) At 9 years of age. (B) At 11 years of age. Follow-up during 2 years reveals rapid development of the full pattern of extreme right ventricular hypertrophy. Limb leads revealed no change in the position of the heart.

Variation in the position of the heart may alter the pattern of the standard and unipolar limb leads, as in Allanby and Campbell's (1949) Case 1, but the chest leads remain characteristic.

The size and shape of the hearts in the four cases with necropsy bore a close resemblance to each other and to those examples of this malformation reported elsewhere. The right atrium was enlarged and hypertrophied, there was enormous hypertrophy of the right ventricle and of the ventricular septum, which curved to the left as it approached the apex. This hypertrophied right ventricle thus formed the entire anterior surface and a large part of the diaphragmatic surface of the heart. The left side of the heart was within normal limits.

The time of onset of the intrinsic deflection in unipolar chest lead V1 was between 0.04 and 0.06 sec. in each case. In only two cases was there notching of the $R$ wave in this lead (Fig. 7 and 8B) and even in these $R^{\prime}$ never occurred later than $0.06 \mathrm{sec}$. The unipolar chest leads thus differed from the pattern of partial right bundle branch block common in large atrial and ventricular septal defects. It was considered that the extreme thickness of the right ventricular wall and the enormous size of the muscle cells could adequately account for the delay of the intrinsic deflection. In none of the specimens were serial sections of the conduction tissue examined. 


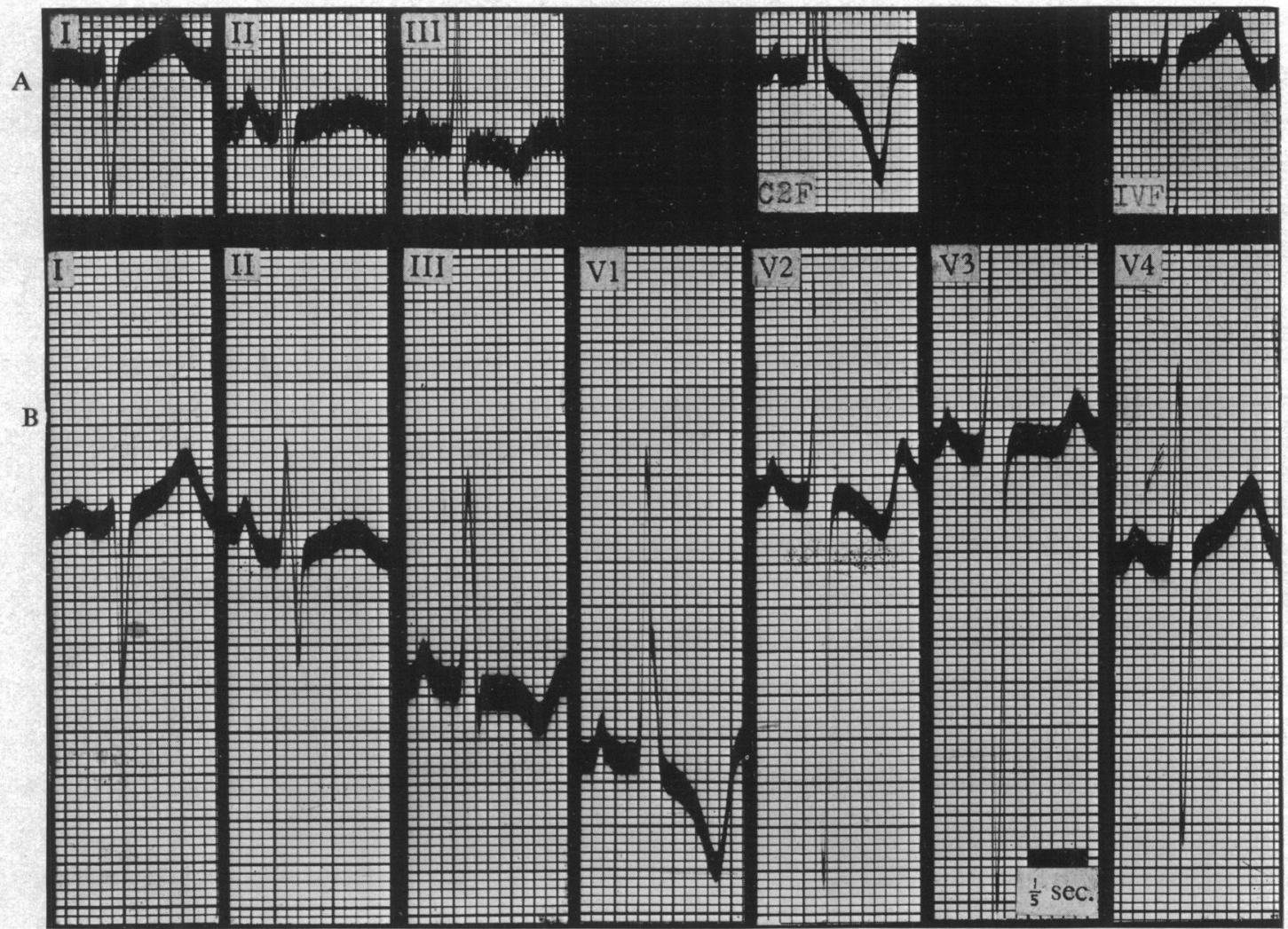

FIG. 8.-Electrocardiogram of Case 7. (A) At 13 years of age. Six months before onset of bacterial endocarditis. Right axis deviation and deep $T$ inversion in C2F. (B) At 16 years of age. Right ventricular hypertrophy but not of extreme degree. Follow-up record at 18 years of age showed no change.

\section{Development of Electrocardiographic Pattern}

In the fotal circulation, if we transfer the findings in lambs to the human subject, the right ventricular output is considerably less in the fotus than in the new-born child. Franklin, Barclay, and Prichard (1946) have shown how the blood returning to the heart in the lamb fotus is shared between the two ventricles; how the blood returning from the placenta and lower half of the body is divided by the caudal edge of the inter-atrial septum into a large stream that passes to the left side of the heart, and a small stream that is joined by the blood from the upper part of the body and passes into the right ventricle. With the opening of the pulmonary circulation at birth and the functional closure of the foramen ovale, the output of the right ventricle is immediately increased. Subsequent growth and activity of the child lead to further increase of the right ventricular output in relation to the relatively static or possibly decreasing (Allanby and Campbell, 1949) size of the stenosed pulmonary orifice. It is suggested that the pulmonary opening may be significantly narrowed in intra-uterine life without stimulating hypertrophy of the right ventricle; that the right ventricle after birth is able to overcome mild degrees of stenosis without developing sufficient hypertrophy for electrocardiographic detection; but that in the more severe grades of stenosis there is a progressive hypertrophy of the right ventricle.

Unipolar electrocardiography, by revealing the degree of this hypertrophy is of very great value in the assessment of the severity of the stenosis. In mild cases the pattern of extreme right ventricular hypertrophy never develops; in moderately severe cases it develops slowly and does not 
reach its peak until adult life; in severe cases it develops rapidly and in childhood; in extreme cases it is present from birth or develops within the first few months of life.

This is not the invariable course. In pulmonary atresia and rare cases of pulmonary stenosis, a greatly increased amount of blood may pass through the foramen ovale to the left side of the heart. There is deep cyanosis from birth, the right ventricle becomes atrophic and the left ventricle hypertrophies. Peacock (1866) gave a good example and quoted several others. Survival beyond the first few days of life is rare and the case reported by Wood (1942), which survived to 6 years of age, is very unusual. More commonly the right atrium persists in feeding the right ventricle.

Unlike lesions that lead to pulmonary congestion, dyspnœa is a relatively late symptom in pulmonary stenosis, and patients with this malformation may lead comparatively normal lives until the right ventricle begins to fail. In the absence of tricuspid incompetence or rheumatic or bacterial endocarditis, congestive heart failure does not occur until the right ventricle has reached its maximum degree of hypertrophy. By revealing the development of this hypertrophy, unipolar electrocardiography provides evidence that precedes change in either the clinical or radiological condition of the patient (Cases 4 and 5). Once the full hypertrophy has developed it may be sufficient to overcome the stenosis for many years (Case 6); especially if the hypertrophy develops slowly and does not reach the extreme degree until adult life. If, on the other hand, the hypertrophy develops rapidly and in childhood, there is the danger of early congestive failure. Cases 1

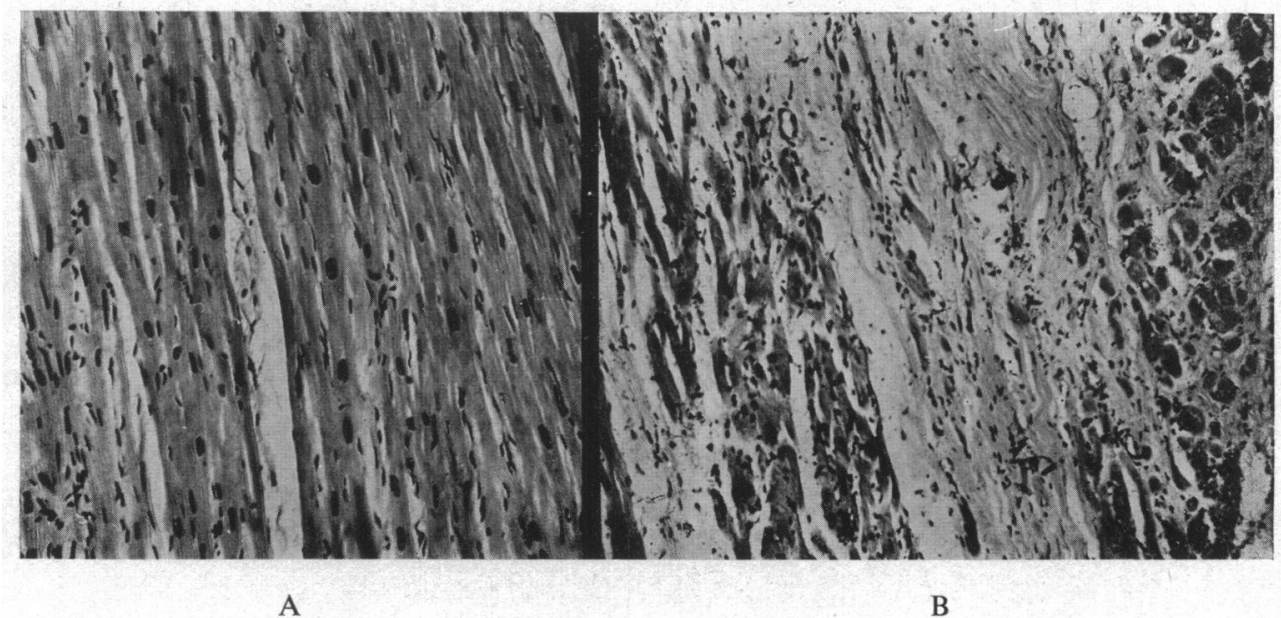

FIG. 9.-Photomicrographs of myocardium $(\times 90)$ of right ventricle and stained with Weigert's iron hæmatoxylin.

(A) Case 3. Large muscle cells but no diffuse fibrosis. (B) Case 6. Large muscle cells with extensive fibrosis.

and 3, Blackford and Parker's (1941) case, Allanby and Campbell's (1949) second case, and the frequency of abrupt cardiac arrest during thoracotomy, suggest that sudden death is more common in this malformation than has been recognized. Acute right ventricular failure appears the most likely explanation.

Allanby and Campbell (1949) have pointed out the frequency of prolongation of the P-R interval. This has not been a feature of the cases reported here, the longest intervals being $\mathbf{0 \cdot 2}$ sec. in Case 2 and $0.18 \mathrm{sec}$. in Case 6 . In the remainder it was $0.16 \mathrm{sec}$. or less.

A more significant difference between these cases and those reported by Allanby and Campbell (1949) is the relative absence of diffuse fibrosis through the myocardium of the right ventricle (Fig. 9). The only heart in which diffuse fibrosis was a striking feature was that from Case 6, the oldest patient, in whom there had been long-standing right ventricular failure. Taken with the cases in which diffuse fibrosis has been reported, this suggests that it is the result of long-standing over-work and not an inherent part of the hypertrophy of the right ventricular wall. 


\section{DifFERENTIAL DiAGNOSIS}

The right ventricle seldom reaches so marked a degree of hypertrophy in any other lesion. congenital or acquired, as it does in isolated pulmonary stenosis. The pattern of extreme right ventricular hypertrophy described, although characteristic of the severe forms, is not seen frequently in clinical cardiography, though it can occur in other lesions.

In the tetralogy of Fallot, the ventricular septal defect and over-riding aorta spare the right ventricle at the expense of the pulmonary circulation. The arterial anoxæmia, secondary polycythæmia, and diminished pulmonary blood flow, are usually responsible for death before the right ventricle fails. Post mortem, the right ventricular wall is seldom thicker than the left, with which it shares its work. The degree of pulmonary stenosis, the size of the ventricular septal defect, and the extent of dextro-position of the aorta, all affect the burden carried by the right ventricle in the tetralogy. This is seen electrocardiographically in a great diversity of patterns of right ventricular hypertrophy. Usually there are tall $R$ waves and inverted $T$ waves in V1 (Fig. 10) with an abrupt

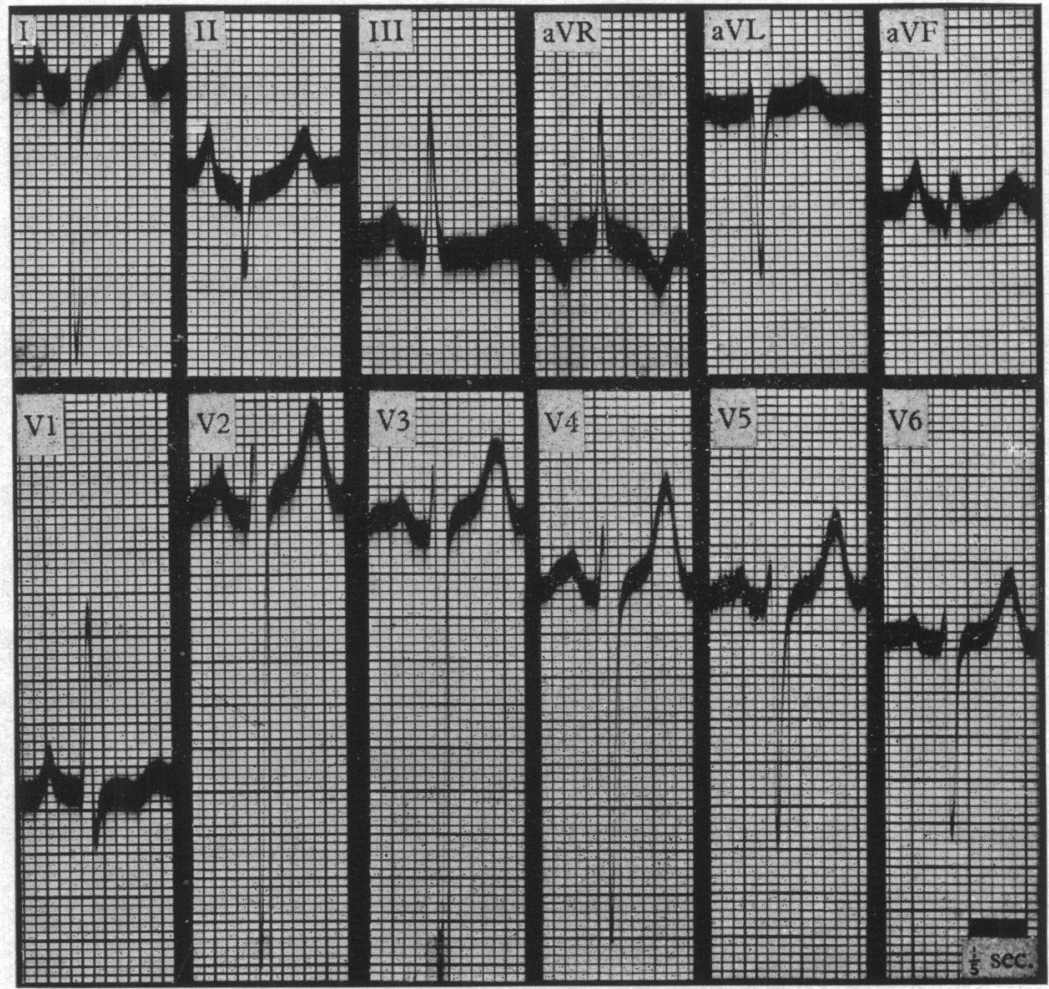

Fig. 10.-Electrocardiogram of girl, aged 12 years, with the tetralogy of Fallot (necropsy confirmation). Most of her life spent in wheel-chair. Frequent cyanotic attacks with loss of consciousness. Death after operation. Note the tall $R$ wave in V1 with abrupt change to small $r$ with deep $S$ waves in V2. Tall $R$ as sole initial deflection in aVR. Deep $S$ in V6.

change to small $\mathrm{r}$ and deep $\mathrm{S}$ waves in V2 or V3. In certain cases the cardiographic diagnosis of right ventricular hypertrophy depends on the recognition of deep $S$ waves in $V 6$ and tall $R$ waves in aVR. Kossmann et al. (1948) give a good example of the abrupt change between V1 and V2 and the characteristic tall $R$ waves in leads V3R to V6R.

The author has not seen the pattern of extreme right ventricular hypertrophy in any case of the tetralogy that has come to necropsy. Nevertheless, clinical experience suggests that it does sometimes occur, possibly when the ventricular septal defect is small and the aorta relatively little 
dextroposed, possibly when there is extreme dextroposition of the aorta and the right ventricle is responsible for both systemic and pulmonary circulations. Whatever the cause this pattern is rare in the tetralogy and common in isolated pulmonary stenosis; its recognition is of value in their differentiation. .

In atrial septal defect the work of the right ventricle is added to by its greatly increased output and sometimes by a rise of peripheral resistance in the lungs. Burrett and White (1945) have suggested that pulmonary arterial sclerosis and vascular thrombosis are common. The author has not, however, seen this pattern of extreme right ventricular hypertrophy in atrial septal defect, though Goldberger (1947) has given an example.

In mitral stenosis electrocardiographic evidence of right ventricular hypertrophy is exceptional and slow to develop. Advanced changes do occasionally occur and the pattern of extreme right ventricular hypertrophy has been seen. In some such cases pericardial adhesions surrounding and constricting the pulmonary artery (Gouley, 1937) may be partially responsible.

In chronic cor pulmonale death is precipitated by the associated pulmonary disease before the right ventricle reaches the extreme degree of hypertrophy, but in idiopathic pulmonary hypertension electrocardiographic changes comparable to those recorded over the left ventricle in systemic hypertension may occur in the right chest leads.

\section{SURGical Significance}

Brock $(1948,1949)$ has shown that pulmonary valvulotomy and infundibular (or lower bulbar) resection are feasible operations. The operative mortality rate is reported as high and the risks involved are only justified in cases in which the outlook is poor.

Once the electrocardiographic pattern of extreme right ventricular hypertrophy has developed in pulmonary stenosis, the severity of the lesion is sure. It is suggested that surgery at this stage is justified in the younger age groups and that, by anticipating clinical deterioration and myocardial fibrosis, the operative mortality rate might be reduced.

From the point of view of surgical follow-up, Case 7 is of great interest. This boy's progress, which has been followed electrocardiographically, suggests, as would be anticipated, that in spite of increased activity and growth the progressive hypertrophy of the right ventricle can be arrested by enlargement of the pulmonary orifice.

\section{SUMMARY}

The electrocardiographic features of seven cases of congenital pulmonary stenosis with intact ventricular septum are reported in illustration of the pattern of extreme right ventricular hypertrophy common in this malformation. The chief characteristics of this pattern are seen in the chest leads: they show tall $R$ waves, $S-T$ depression, and deep inversion of the $T$ waves extending far across the left side of the chest.

The diagnosis is supported by necropsy findings in four of the cases.

It is suggested that the right ventricle hypertrophies in proportion to the degree of the stenosis in relation to the right ventricular output, and that unipolar electrocardiography, by recording the extent of the hypertrophy, affords an accurate measure of the severity of the stenosis.

Evidence is presented to show that the development of the electrocardiographic pattern described precedes clinical deterioration, change in the radiological appearance of the heart, onset of right ventricular failure, and diffuse fibrosis of the myocardium. This pattern is characteristic irrespective of heart size on radioscopy, patency of the foramen ovale, exact site of the stenosis, and the state of the pulmonary artery beyond the stenosis.

The significance of this electrocardiographic pattern is discussed in relation to diagnosis, prognosis, and surgical treatment of the malformation.

In the absence of necropsy material, the electrocardiographic pattern of fully developed right bundle branch block, which sometimes occurs in this malformation, is not considered in this paper. 
I wish to express my thanks to Dr. A. Rae Gilchrist for his help and encouragement in the preparation of this paper and for permission to report Cases 2, 3, 4, 5, and 7; to Dr. I. G. W. Hill for helpful criticisms on the electrocardiograms and for permission to report Case 1; to Dr. John Duckworth for anatomical examination of the specimens and the preparation of Fig. 10; to Dr. Fergus Hewat for access to his clinical records of Case 6; to Mr. Andrew Logan for permission to examine the heart in Case 6; to Mr. R. P. Danskin and the staff of the Electrocardiograph Department of the Royal Infirmary, Edinburgh, for their infinite pains in the preparation of the electrocardiograms.

\section{REFERENCES}

Allanby, K. D., and Campbell, M. (1949). Guy's Hosp. Rep., 98, 18.

Auerbach, S. H., and Harper, H. T. (1947). Amer. Heart J., 34, 131.

Blackford, L. M., and Parker, F. P. (1941). Arch. intern. Med., 67, 1107.

Brock, R. C. (1948). Brit. med. J., 1, 1121. (1949). Ibid., $2,399$.

Brown, J. W. (1949). Post-Grad. med. J., 25, 511.

Burrett, J. B., and White, P. D. (1945). Amer. J. med. Sci., 209, 355.

Currens, J. H., Kinney, T. D., and White, P. D. (1945). Amer. Heart J., 30, 491.

Dow, J. W., Levine, H. D., Elkin, M., Haynes, F. W., Hellems, H. K., Whittenberger, J. W., Ferris, B. G., Goodale, W. T., Harvey, W. P., Eppinger, E. C., and Dexter, L. (1950). Circulation, 1, 267.

Franklin, K. J., Barclay, A. E., and Prichard, M. M. L. (1946). The Circulation in the Fetus. Oxford: Blackwell Scientific Publications, Ltd.

Freed, A. N., and Budnitz, J. (1946). Amer. Heart J., 31, 369.

Goldberger, E. (1947). Unipolar Lead Electrocardiography. London: Henry Kimpton.

Gouley, B. A. (1937). Amer. Heart J., 13, 470.

Kossmann, C. E., Berger, A. R., Brumlik, J., and Briller, S. A. (1948). Ibid., 35, 309.

Lowance, M. I., Jones, E. C., Matthew, W. B., and Dunstan, E. M. (1948). Ibid., 35, 820.

Peacock, T. B. (1866). Malformations of the Heart. London: Churchill, 2nd ed.

Pollack, A. A., Taylor, B. E., Odel, H. M., and Burchell, H. B. (1948). Proc. Mayo Clin., 23, 516.

Selzer, A., Carnes, W. H., Noble, C. A., Higgins, W. H., and Holmes, R. O. (1949). Amer. J. Med., $6,3$.

Wood,'P. (1942). Brit. Heart J., 4, 11. 